\title{
RESÍDUO DESIDRATADO DE VITIVINÍCOLAS ASSOCIADO A DIFERENTES FONTES ENERGÉTICAS NA ALIMENTAÇÃO DE OVINOS: CONSUMO E DIGESTIBILIDADE APARENTE ${ }^{1}$
}

\author{
Winery dehydrated residues wineries associated to different energetic sources in \\ sheep feeding: Intake and nutrients digestibility
}

\author{
Daerson Dantas Barroso ${ }^{2}$, Gherman Garcia Leal de Araújo ${ }^{3}$, Divan Soares da Silva ${ }^{4}$, Fernando Thomaz Medina ${ }^{5}$
}

\begin{abstract}
RESUMO
O consumo e a digestibilidade aparente dos nutrientes foram determinados em ovinos confinados, objetivando avaliar a combinação do resíduo desidratado de vitivinícolas a diferentes fontes energéticas. Foram utilizados dezoito ovinos não castrados, com idade aproximada de sete meses e $21 \mathrm{~kg}$ de peso vivo, distribuídos num delineamento em blocos casualizados com três tratamentos e seis repetições. As dietas foram compostas de $50 \%$ de resíduo de vitivinícolas e $50 \%$ de concentrados energéticos: grão de milho moído (Zea mays L.) (T1), raspa de mandioca (Manihot esculenta Crantz) enriquecida com 1,8\% de uréia (T2) e farelo de palma forrageira (Opuntia fícus-indica L.) enriquecido com 1,1\% de uréia (T3). As maiores ingestões foram observadas para as combinações de resíduo com grão de milho moído e resíduo com farelo de palma, respectivamente, com valores para a matéria seca de 84,34 e 107,37 g/PV $/ 75 /$ dia/animal, proteína bruta 133 e $160 \mathrm{~g} /$ dia/animal e NDT 461 e $497 \mathrm{~g} / \mathrm{dia} /$ animal. As digestibilidades da matéria seca, proteína bruta e fibra em detergente neutro foram de 52,89, 47,12 e 42,37; 54,36, 49,63 e 54,95; 36,96, 34,22 e 32,82 \%, respectivamente para as dietas com grão de milho, raspa de mandioca e farelo de palma. Os resultados obtidos para o consumo e para a digestibilidade aparente dos nutrientes, revelaram um bom potencial do resíduo de vitivinícolas combinado as fontes energéticas estudadas.
\end{abstract}

Termos para indexação: Farelo de palma, grão de milho, raspa de mandioca, valor nutritivo.

\begin{abstract}
To evaluate the diet combination of the dried winery residue with different energy sources, intake and apparent digestibility were determined in feedlot sheep. Eighteen male sheep with seven months of age, non-defined breed, weighting initially $21 \mathrm{~kg}$, were used, distributed in a randomized blocks design with three treatments and six replication. The diets were composed with 50\% of dried grapes residue and 50\% of energetic concentrate: corn meal (Zea mays L.) (T1), cassava meal (Manihot esculenta Crantz) enriched with $1,8 \%$ of urea (T2) and cactus meal (Opuntia ficus-indica L.) enriched with 1,1\% of urea (T3). The greatest intake were observed in the combinations of dried winery residue with corn meal and cactus meal and the dry matter intake were, respectively, 84,34 and $107,37 \mathrm{~g} / \mathrm{PV}^{0,75} /$ day; crude protein intake were 133 and $160 \mathrm{~g} /$ day and TDN were 461 and $497 \mathrm{~g} / \mathrm{day}$. The dry matter, crude protein and neutral detergent fiber digestibility coefficients were 52.89, 47.12 and $42.37 ; 54.36,49.63$ and 54.95; 36.96, 34.22 and 32,82\%, respectively, for the corn meal diet, cassava meal and cactus meal. The results for the intake and digestibility coefficients revealed that dried winery residue has good potential to be used to feed sheep in combination with different energy sources.
\end{abstract}

Index terms: Cactus meal, corn grain, cassava meal, alternative feedstuff.

(Recebido para publicação em 2 de junho de 2005 e aprovado em 8 de abril de 2006)

\section{INTRODUÇÃO}

Em decorrência da irregularidade na oferta quantitativa e qualitativa dos recursos forrageiros da região semi-árida brasileira, devido às altas variações climáticas, a produtividade animal nesta região é bastante comprometida. Assim sendo, o uso de alternativas alimentares (resíduos agroindustriais, bancos de proteína, fenos, silagens e concentrados), têm sido freqüentemente recomendadas para criadores da região, no intuito de suprir a deficiência nutricional dos rebanhos (SOUTO et al., 2001).
O consumo voluntário é destacado por Noller \& Nascimento Júnior (1982), como fundamental para determinar o desempenho animal, pois é o primeiro fator influenciador do ingresso de nutrientes, principalmente energia e proteína, necessários ao atendimento das exigências de mantença e produção animal. Segundo Mertens (1987), 60 a 90\% das variações no desempenho animal são atribuídas ao consumo de nutrientes, enquanto 10 a $40 \%$, à digestibilidade dos nutrientes.

${ }^{1}$ Parte da Dissertação de Mestrado do primeiro autor

${ }^{2}$ Mestre em Zootecnia - Rua Conde Deu, 184 - Centro - 56.306-060 - Petrolina, PE - daersonbarroso@yahoo.com.br

${ }^{3}$ Pesquisador III da Embrapa Semi-Árido - BR 428, Km 152, Zona Rural - Cx.P. 23 - 56.302-970 - Petrolina, PE - ggla@cpatsa.embrapa.br

${ }^{4}$ Professor Adjunto Departamento de Zootecnia do Centro de Ciências Agrárias/CCA/UFPB - 58.397-000 - Areia,PA - divan@cca.ufpb.br

${ }^{5}$ Mestre em Zootecnia - CEFET Petrolina - Unidade Agrícola - BR 235, Km 22 - Proj. Sen. Nilo Coelho-N4 - Cx. P. 178 - 56.300-000 - Pertrolina, PE thomazmedina@bol.com 
A regulação de ingestão de alimento pelos ruminantes é feita principalmente por dois processos: distensão ruminal e densidade energética (MERTENS, 1987). Todavia, Raymond (1969), cita que nas forragens com baixo teor de proteína na matéria seca (MS) (4 a 6\%), o consumo seria limitado pela baixa disponibilidade de nitrogênio para os microorganismos do rúmen.

Segundo Araújo (2003), os estudos das formas de utilização dos resíduos agroindustriais, a exemplo do subproduto da indústria do vinho, desidratado ou ensilado, poderá garantir um bom aporte de nutrientes para os animais, principalmente no período de maior escassez de forragem, podendo esses nutrientes ser convertidos em produtos nobres como a carne, a pele e o leite.

O resíduo de vitivinícolas possui bons teores em proteína bruta e carboidratos totais, 14,77 e $66,00 \%$, respectivamente (DANTAS et al., 2004), porém, a digestibilidade da proteína bruta do resíduo de uva oriundo da produção de suco é baixa (LIMA \& LEBOUTE, 1986), com baixos teores de energia.

O elevado coeficiente de digestibilidade e a riqueza em energia, principalmente carboidratos solúveis, destacada para o milho, mandioca e palma forrageira, os condicionam como recursos potenciais para garantir um bom aporte deste componente nutricional, que quantitativamente é o mais importante.

A digestibilidade constitui outro importante parâmetro do valor nutritivo de um alimento (OLIVEIRA et al., 1991). Segundo Barros et al. (1997), a digestibilidade é a capacidade do alimento em permitir que o animal utilize seus nutrientes em menor ou maior escala. Ao longo do tempo, vários ensaios com diversas dietas tem sido conduzidos com ovinos, caprinos e bovinos para medir o consumo e avaliar a digestibilidade destas.

Com a realização deste trabalho, objetivou-se avaliar a combinação do resíduo desidratado de vitivinícolas a diferentes fontes energéticas em dietas para ovinos terminados em confinamento, sobre o consumo e a digestibilidade aparente dos nutrientes.

\section{MATERIAL E MÉTODOS}

O experimento foi realizado no período de abril a maio de 2004, no Setor de Nutrição Animal da Embrapa Semi-Árido, em Petrolina-PE.

Foram utilizados 18 ovinos sem padrão racial definido, não castrados, com idade aproximada de sete meses, oriundos de sistemas extensivos de produção em caatinga, com peso vivo médio inicial de $21 \mathrm{~kg}$ e distribuídos num delineamento experimental em blocos casualizados com três tratamentos e seis repetições, considerando o peso vivo inicial como fator de controle.

Previamente ao início do experimento, os animais foram identificados com brincos numerados, vermifugados, pesados, sorteados em seus tratamentos e mantidos em baias individuais contendo água, alimento e mistura mineral à vontade.

Foram formuladas três dietas com base nas exigências nutricionais para ovinos com $30 \mathrm{~kg}$ de peso vivo e ganho de peso esperado de $200 \mathrm{~g} / \mathrm{dia}$, segundo NRC (1975), para um consumo de 4,3\% do peso vivo de MS e teores de $11,0 \%$ de PB e 64\% de NDT na MS total da dieta.

As dietas foram compostas de resíduo desidratado de vitivinícolas como volumoso, combinado com um ingrediente energético em cada tratamento na proporção de 50:50 base da matéria seca: grão de milho moído (Zea mays L.) (T1), raspa de mandioca (Manihot esculenta Crantz) enriquecida com 1,8\% de uréia (T2) e farelo de palma forrageira (Opuntia fícus-indica L.) enriquecido com $1,1 \%$ de uréia (T3). O enriquecimento das dietas com uréia foi feito objetivando torná-las isoprotéicas.

O resíduo foi doado pela Vitivinícola Santa Maria LTDA, resultante do processamento das uvas para a produção de vinho, sendo basicamente composto de casca, semente e polpa. O grão de milho moído, a raspa de mandioca e o farelo de palma foram processados no Setor de Nutrição Animal da Embrapa Semi-Árido, sofrendo secagem e trituração de seus respectivos materiais de origem.

As dietas foram oferecidas duas vezes ao dia, às $8 \mathrm{e}$ 15 horas, durante todo o período experimental, ajustando-se uma sobra diária de aproximadamente $20 \%$ do oferecido por animal. A composição química-bromatológica dos ingredientes e das dietas é mostrada nas Tabelas 1 e 2, respectivamente.

Para a determinação do consumo e dos coeficientes de digestibilidade aparente dos nutrientes das dietas, foi realizado um ensaio de digestibilidade que constou de 14 dias de adaptação e cinco dias de coleta total de dados.

No período de coletas, diariamente foram feitas anotações da quantidade de alimento oferecido e sobras para cada animal, além de amostragem dos ingredientes oferecidos e das sobras. As fezes foram coletadas em sacolas adaptadas aos animais nos cinco dias do período de coleta, às $8 \mathrm{e}$ às 14 horas, sendo, em seguida, registrado o peso. Todo o material coletado (oferecido, sobras e fezes) foi devidamente identificado e armazenado para posteriores análises. 
TABELA 1 - Teores médios de matéria seca (MS), matéria orgânica (MO), matéria mineral (MM), proteína bruta (PB), fibra em detergente neutro (FDN), fibra em detergente ácido (FDA), extrato etéreo (EE), carboidratos totais (CHOT), lignina (LN) e digestibilidade "in vitro" da matéria seca (DIVMS), dos ingredientes utilizados na formulação das dietas, expressos na matéria seca.

\begin{tabular}{lcccc}
\hline Parâmetros (\%) & $\begin{array}{c}\text { Resíduo de } \\
\text { vitivinícolas }\end{array}$ & Grão de milho moído & Raspa de mandioca & Farelo de palma \\
\hline MS & 90,60 & 89,20 & 89,43 & 89,00 \\
MO & 87,72 & 97,04 & 95,64 & 81,05 \\
MM & 12,28 & 2,95 & 4,36 & 18,05 \\
PB & 17,00 & 8,46 & $8,19 *$ & $8,50^{* *}$ \\
FDN & 60,36 & 15,46 & 16,42 & 40,90 \\
FDA & 52,19 & 5,18 & 10,89 & 31,87 \\
EE & 5,15 & 6,66 & 0,58 & 0,70 \\
CHOT & 65,57 & 81,93 & 92,06 & 76,25 \\
LN & 22,00 & 0,61 & 2,05 & 3,88 \\
DIVMS & 30,00 & 76,53 & 62,83 & 60,72 \\
\hline
\end{tabular}

*raspa de mandioca $+1,8 \%$ de uréia $* *$ farelo de palma $+1,1 \%$ de uréia.

TABELA 2 - Composição percentual média das dietas e os respectivos teores médios de matéria seca (MS), matéria orgânica (MO), matéria mineral (MM), proteína bruta (PB), fibra em detergente neutro (FDN), fibra em detergente ácido (FDA), extrato etéreo (EE), carboidratos totais (CHOT), lignina (LN) e NDT, expressos na matéria seca.

\begin{tabular}{lccc}
\hline Parâmetros (\%) & $\begin{array}{c}\mathbf{5 0 \%} \text { de resíduo + 50\% de } \\
\text { grão de milho }\end{array}$ & $\begin{array}{c}\mathbf{5 0 \%} \text { de resíduo + 50\% de } \\
\text { raspa de mandioca }\end{array}$ & $\begin{array}{c}\mathbf{5 0 \%} \text { de resíduo + 50\% de } \\
\text { farelo de palma }\end{array}$ \\
\hline MS & 89,90 & 90,01 & 89,80 \\
MO & 92,38 & 91,68 & 84,38 \\
MM & 7,61 & 8,32 & 15,16 \\
PB & 12,73 & 12,59 & 12,75 \\
FDN & 37,91 & 38,39 & 50,63 \\
FDA & 28,68 & 31,54 & 42,03 \\
EE & 5,90 & 2,86 & 2,92 \\
LN & 11,30 & 12,02 & 12,94 \\
CHOT & 73,75 & 78,81 & 70,91 \\
NDT & 45,73 & 43,31 & 40,00 \\
\hline
\end{tabular}

Para os ingredientes oferecidos, sobras e fezes, foram feitas amostras compostas das coletas diárias referentes ao período de digestibilidade composto por cinco dias, por animal.

As análises de matéria seca (MS), matéria orgânica (MO), matéria mineral (MM), proteina bruta (PB), fibra em detergente neutro (FDN), fibra em detergente ácido (FDA), extrato etéreo (EE) e lignina (LN) foram realizadas no Laboratorio de Nutrição Animal da Embrapa SemiÁrido, segundo metodologia descrita por Silva \& Queiroz (2002).

Os coeficientes de digestibilidade foram calculados por: (Nutriente Ingerido - Nutriente Excretado
/ Nutriente Ingerido) x 100 (SILVA \& LEÃO, 1979).

Os carboidratos totais (CHOT) foram obtidos pela equação, $100-(\% \mathrm{~PB}+\quad \mathrm{EE}+\% \mathrm{MM})$, o consumo de nutrientes digestiveis totais (NDT) foi calculado segundo Sniffen et al. (1992) pela equação $\mathrm{cNDT}=(\mathrm{cPB}-\mathrm{PBf})+$ 2,25 (cEE - EEf $)+($ cCHOT - CHOTf $)$, e os teores de nutrientes digestíveis totais (NDT) das dietas pela relação entre a ingestão de matéria seca e NDT, segundo Veras et al. (2000).

As variáveis estudadas foram avaliadas utilizandose o SAS Institute (2004) com níveis de 5\% de probabilidade e teste de Duncan para comparação das médias. 


\section{RESULTADOS E DISCUSSÃO}

Verificou-se que a fonte energética associada ao resíduo de vitivinícolas afetou $(\mathrm{P}<0,05)$ o consumo de MS em $\mathrm{g} / \mathrm{dia}, \% \mathrm{PV}$ e $\mathrm{g} / \mathrm{PV}^{0,75}$, com valores superiores para as combinações do resíduo com farelo de palma e resíduo com grão de milho moído em relação à raspa de mandioca (Tabela 3).

Os resultados encontrados na literatura com ovinos tem revelado uma menor aceitabilidade pela raspa em relação a outros ingredientes, o qual foi observado por Araújo \& Moreira (2001), relatando consumos decrescentes com o aumento de participação da raspa de mandioca na dieta e, reforçado neste trabalho, onde a menor aceitabilidade pela raspa de mandioca se refletiu em reduções de 22,12, 15,80 e 17,44\% para consumo de matéria seca em g/dia, \%PV e g/UTM, respectivamente em relação ao grão de milho moído e 36,84, 32,16 e 33,67\% em relação ao farelo de palma (Tabela 3 ).

Observou-se para a dieta composta de resíduo e farelo de palma, maior consumo de MS, que pode ser explicado pelos menores teores de energia refletidos nos valores inferiores de NDT e superiores de FDN desta dieta (Tabelas 2 e 3), visto que, o consumo de MS pelos ruminantes está primeiramente relacionado a sua necessidade de energia, e tem este cessado quando sua necessidade energética é suprida.
A semelhança no consumo de MS entre as dietas que combinam o resíduo com o grão de milho moído e com o farelo de palma, está de acordo com os resultados obtidos por Veras et al. (2002), avaliando o consumo de dietas com quatro níveis de substituição do milho pelo farelo de palma e sem alteração do consumo.

O NRC (1985) recomenda um consumo de MS de $51,02 \mathrm{~g} / \mathrm{PV}^{0,75}$ para a manutenção de ovinos de $25 \mathrm{~kg}$ de peso vivo, portanto, atendido pelas três combinações avaliadas neste trabalho (Tabela 3). Lima \& Leboute (1986) obtiveram baixo consumo de MS em caprinos e ovinos alimentados exclusivamente com resíduo de uva, verificando ingestão média de $35,6 \mathrm{~g} / \mathrm{PV}^{0,75}$, havendo aumento significativo com a adição de feno de alfafa em níveis crescentes. Os mesmos autores observaram que o resíduo puro é de baixo consumo voluntário, porém, quando misturado a outros ingredientes Lima \& Leboute (1986) revelaram que o consumo total de MS não foi afetado, o que é comprovado no presente trabalho pelos bons índices de ingestão de MS observados para as misturas avaliadas. Dantas et al. (2004), alimentando carneiros exclusivamente com o resíduo de vitivinícolas, observaram consumo de matéria seca de $53,5 \mathrm{~g} / \mathrm{PV}^{0,75}$, atendendo portanto a exigência de ingestão de matéria seca para manutenção de ovinos com $25 \mathrm{~kg}$ de peso vivo descrita pelo NRC (1985) que é de 51,02 (g/PV $\left.{ }^{0,75}\right)$.

TABELA 3-Médias e coeficiente de variação (CV), para o consumo expresso em g/dia, \%PV e g/PV ${ }^{0,75}$ da matéria seca (MS), matéria orgânica (MO), proteína bruta (PB), fibra em detergente neutro (FDN) e nutrientes digestíveis totais (NDT).

\begin{tabular}{lcccc}
\hline Parâmetros & $\begin{array}{c}\mathbf{5 0 \%} \text { de resíduo }+ \\
\mathbf{5 0 \%} \text { de grão de } \\
\text { milho moído }\end{array}$ & $\begin{array}{c}\mathbf{5 0 \%} \text { de resíduo + } \\
\mathbf{5 0 \%} \text { de raspa de } \\
\text { mandioca }\end{array}$ & $\begin{array}{c}\mathbf{5 0 \%} \text { de resíduo + } \\
\mathbf{5 0 \%} \text { de farelo de } \\
\text { palma }\end{array}$ & CV (\%) \\
\hline CMS (g/dia) & $888 \mathrm{a}$ & $785 \mathrm{~b}$ & $1123 \mathrm{a}$ & 21,61 \\
$\mathrm{CMS}(\% \mathrm{PV})$ & $3,84 \mathrm{a}$ & $3,67 \mathrm{~b}$ & $4,87 \mathrm{a}$ & 18,71 \\
$\mathrm{CMS}\left(\mathrm{g} / \mathrm{PV}^{0,75}\right)$ & $84,34 \mathrm{a}$ & $79,12 \mathrm{~b}$ & $107,37 \mathrm{a}$ & 18,71 \\
$\mathrm{CPB}(\mathrm{g} / \mathrm{dia})$ & $133 \mathrm{a}$ & $115 \mathrm{~b}$ & $160 \mathrm{a}$ & 22,75 \\
$\mathrm{CPB}(\% \mathrm{PV})$ & $0,60 \mathrm{a}$ & $0,48 \mathrm{~b}$ & $0,70 \mathrm{a}$ & 19,38 \\
$\mathrm{CPB}\left(\mathrm{g} / \mathrm{PV}^{0,75}\right)$ & $13,20 \mathrm{a}$ & $10,72 \mathrm{~b}$ & $15,53 \mathrm{a}$ & 19,83 \\
$\mathrm{CFDN}(\mathrm{g} / \mathrm{dia})$ & $417 \mathrm{~b}$ & $383 \mathrm{~b}$ & $675 \mathrm{a}$ & 20,56 \\
$\mathrm{CFDN}(\% \mathrm{PV})$ & $1,79 \mathrm{~b}$ & $1,77 \mathrm{~b}$ & $2,94 \mathrm{a}$ & 16,10 \\
$\mathrm{CFDN}\left(\mathrm{g} / \mathrm{PV} V^{0,75}\right)$ & $39,27 \mathrm{~b}$ & $38,36 \mathrm{~b}$ & $64,42 \mathrm{a}$ & 16,91 \\
$\mathrm{CNDT}(\mathrm{g} / \mathrm{dia})$ & $461 \mathrm{a}$ & $340 \mathrm{~b}$ & $497 \mathrm{a}$ & 25,30 \\
\hline
\end{tabular}

Médias seguidas de letras diferentes na mesma linha diferem estatisticamente a 5\% de significância pelo teste de Duncan.

Ciênc. agrotec., Lavras, v. 30, n. 4, p. 767-773, jul./ago., 2006 
O consumo de $\mathrm{PB}$ sofreu efeito $(\mathrm{P}<0,05)$ da fonte energética associada ao resíduo. Os animais que receberam as combinações de resíduo com farelo de palma e resíduo com grão de milho moído, os quais apresentaram maior consumo de MS, ingeriram também maior quantidade de $\mathrm{PB}$ em g/dia, \%PV e g/PV ${ }^{0,75}$ do que aqueles que receberam resíduo com raspa de mandioca. Apesar das dietas serem isoprotéicas, os animais exerceram uma forte seleção alimentar e apresentaram ainda um comportamento seletivo diferenciado entre eles, em função provavelmente da individualidade do animal e da composição heterogênea do resíduo, que podem ter contribuído para as diferenças no consumo de PB.

Os requerimentos de consumo $\mathrm{PB}$ recomendados pelo NRC (1985), para a manutenção de ovinos com $25 \mathrm{~kg}$ de peso vivo, que é de $31,8 \mathrm{~g} / \mathrm{dia}$, foram totalmente atendidos, porém, os requerimentos de ingestão de PB para um ganho de $200 \mathrm{~g} / \mathrm{dia}$, ou seja, $143 \mathrm{~g} / \mathrm{dia}$, atendidos em 93,00 \% na dieta de resíduo com grão de milho moído, $80,41 \%$ na dieta de resíduo com raspa de mandioca e totalmente atendidos na dieta de resíduo com farelo de palma, resultado provável da maior ingestão total de MS observada para esta dieta (Tabela 3).

O máximo consumo da fração de FDN (Tabela 3) ocorreu para a dieta de resíduo com farelo de palma $675 \mathrm{~g} /$ dia, sendo superior as outras combinações, resultado da maior ingestão total de MS e maior concentração de FDN nesta combinação (Tabelas 2 e 3). Os dados médios de consumo de FDN para as três dietas avaliadas são superiores aos encontrados por Dantas et al. (2004), com alimentação exclusiva de resíduo de vitivinícolas, $236 \mathrm{~g}$ para FDN, demonstrando o benefício da combinação do resíduo com outros ingredientes sobre a ingestão de nutrientes.
A exemplo da maioria dos outros nutrientes, houve menor ingestão diária $(\mathrm{P}<0,05)$ de NDT para a combinação de resíduo com raspa de mandioca (340 g), ficando 59\% abaixo do recomendado pelo NRC (1975), que é de $830 \mathrm{~g} /$ dia para um ganho esperado de $200 \mathrm{~g} / \mathrm{dia}$. Este resultado pode ter consequências negativas para o desempenho animal, visto que a energia desempenha funções vitais para o organismo e quantitativamente representa a maior parte do requerimento animal. As outras combinações apresentaram consumo de NDT semelhantes $(\mathrm{P}>0,05)$, porém, com valores também abaixo dos recomendados pelo NRC (1975), havendo déficit de 44 e $40 \%$ no atendimento dos referidos requerimentos para as associações de resíduo com grão de milho e resíduo com farelo de palma, respectivamente. Esses resultados podem ser justificados pelo elevado teor de lignina do (Tabela 1) comprometendo expressivamente a ingestão de NDT e revelando a dificuldade de atendimento das necessidades energéticas em sistemas com uso de alguns recursos forrageiros disponíveis regionalmente e/ou alternativos, como é o caso dos resíduos.

Os coeficientes de digestibilidade foram influenciados $(\mathrm{P}<0,05)$ pelo concentrado energético associado ao resíduo de vitivinícolas (Tabela 4). A digestibilidade aparente da MS e FDN para a dieta contendo grão de milho foi superior $(\mathrm{P}<0,05)$ à verificada para as dietas de raspa de mandioca e farelo de palma, que por sua vez não diferiram entre si $(\mathrm{P}>0,05)$. $\mathrm{O}$ milho possui maiores proporções de amido em relação à raspa de mandioca e farelo de palma, sendo este tipo de carboidrato mais rapidamente degradado. Os resultados digestibilidade "in vitro" da matéria seca apresentados na Tabela 1, mostram superioridade para o grão de milho moído em relação as outras fontes de energia.

TABELA 4 - Médias e coeficiente de variação (CV), para o coeficiente de digestibilidade (CD), da matéria seca (MS), proteína bruta (PB), fibra em detergente neutro (FDN) e carboidratos totais (CHOT).

\begin{tabular}{lcccc}
\hline Parâmetros (\%) & $\begin{array}{c}\mathbf{5 0 \%} \text { de resíduo }+ \\
\mathbf{5 0 \%} \text { de grão de } \\
\text { milho moído }\end{array}$ & $\begin{array}{c}\mathbf{5 0 \%} \text { de resíduo }+ \\
\mathbf{5 0 \%} \text { de raspa de } \\
\text { mandioca }\end{array}$ & $\begin{array}{c}\mathbf{5 0 \%} \text { de resíduo + } \\
\mathbf{5 0 \%} \text { de farelo de } \\
\text { palma }\end{array}$ & CV (\%) \\
\hline CDMS & $52,89 \mathrm{a}$ & $47,12 \mathrm{~b}$ & $42,37 \mathrm{~b}$ & 14,03 \\
CDPB & $54,36 \mathrm{a}$ & $49,63 \mathrm{a}$ & $54,95 \mathrm{a}$ & 13,40 \\
CDFDN & $36,96 \mathrm{a}$ & $34,22 \mathrm{~b}$ & $32,82 \mathrm{~b}$ & 7,08 \\
CDCHOT & $49,04 \mathrm{a}$ & $46,02 \mathrm{a}$ & $41,46 \mathrm{a}$ & 14,30 \\
\hline
\end{tabular}

Médias seguidas de letras diferentes na mesma linha diferem estatisticamente a $5 \%$ de significância pelo teste de Duncan. 
Muitos resultados encontrados na literatura mostram elevados coeficientes de digestibilidade dos nutrientes para o milho, a mandioca e a palma, porém, a associação desses ingredientes energéticos ao resíduo de vitivinícolas que apresenta baixa digestibilidade "in vitro" da matéria seca (Tabela 1), reduziu os coeficientes de digestibilidade da matéria seca e conseqüentemente dos nutrientes (Tabela 4). Os coeficientes de digestibilidade da MS, obtidos no presente estudo para as três dietas estão dentro da faixa dos coeficientes relatados por Barros et al. (1997), em uma vasta revisão sobre o assunto.

Quanto à digestibilidade da fibra, representada na fração de FDN, observaram-se baixos coeficientes para as três combinações avaliadas, que podem ser atribuídos a elevada concentração de lignina no resíduo (Tabela 1), caracterizando a baixa qualidade desta fibra. Lima \& Leboute (1986), também observaram baixa digestibilidade da fibra para o resíduo de uva processada para a produção de suco, obtendo valores de 28,08 e 27,44\% para ovinos e caprinos, respectivamente. Barros et al. (1997) e Soest (1994) apontam a lignificação da parede celular como o principal fator de indigestibilidade das forragens.

Os coeficientes de digestibilidade da PB e dos CHOT não foram influenciados $(\mathrm{P}>0,05)$ pelo concentrado energético. A adição de uma fonte de nitrogênio nãoprotéico (uréia) em duas combinações testadas, pode ter equilibrado os coeficientes de digestibilidade. Gonzaga Neto et al. (2001) também observaram semelhança entre os coeficientes de digestibilidade da $\mathrm{PB}$ em duas dietas à base de feno de catingueira e acrescidas de uréia. As digestibilidades encontradas na literatura para os concentrados energéticos utilizados neste trabalho são elevadas, porém, a associação com o resíduo de vitivinícolas, reduziu a digestibilidade da proteína, talvez em função da indisponibilidade da proteína relatada por Barros et al. (1997) e Lima \& Leboute (1986) para o resíduo de uva, que atribuem a baixa digestibilidade da proteína a associações a taninos e antocianinas da uva. Vale também ressaltar a ampla lignificação apresentada pelo resíduo de vitivinícolas (Tabela 1), causando efeitos significativos na redução da digestibilidade dos nutrientes.

\section{CONCLUSÕES}

A formulação de dietas com o resíduo desidratado de vitivinícolas em combinação ao grão de milho moído, raspa de mandioca e farelo de palma, mostrou boa capacidade de aporte de nutrientes para ovinos em confinamento, não comprometendo o consumo no nível de 50\% de participação estudado, porém, comprometendo a digestibilidade, possivelmente em função do alto teor de lignina do resíduo.

Outros estudos de avaliação do potencial do resíduo de vitivinícolas como fonte volumosa em dietas para ovinos e caprinos, deverão ser realizadas para derivar outras respostas biológicas, a exemplo do desempenho animal.

\section{REFERÊNCIAS BIBLIOGRÁFICAS}

ARAÚJO, G. G. L. de. Avaliação do potencial forrageiro do resíduo de uva de vitivinícolas e estudo de dietas para caprinos e ovinos no vale do São Francisco. Brasília, DF: Embrapa Semi-Árido, 2003.

ARAÚJO, G. G. L. de; MOREIRA, J. N. Feno de maniçoba: uma alternativa de volumoso para ovinos no Semi-árido brasileiro: consumo, digestibilidade e desempenho animal. Brasília, DF: Embrapa Semi-Árido, 2001. (Boletim de pesquisa e desenvolvimento, 59).

BARROS, N. N.; SOUSA, F. B. de; ARRUDA, F. de A. V. Utilização de forrageiras e resíduos agroindustriais por caprinos e ovinos. Brasília, DF: Embrapa Caprinos, 1997. (Documentos, 26).

DANTAS, F. R.; ARAÚJO, G. G. L. de; SOUZA, C. M. S. de. Composição química e consumo de nutrientes do resíduo de uva em caprinos e ovinos no vale do São Francisco. In: CONGRESSO NORDESTINO DE PRODUÇÃO ANIMAL, 3., 2004, Campina Grande, PB. Anais... Campina Grande: Congresso Nordestino de Produção Animal, 2004. CDROM.

GONZAGA NETO, S.; BATISTA, A. M. V.; CARVALHO, F. F. R. Composição bromatológica, consumo e digestibilidade in vivo de dietas com diferentes níveis de feno de catingueira (Caesalpinea bracteosa), fornecidas para ovinos morada nova. Revista Brasileira de Zootecnia, Viçosa, v. 30, n. 2, p. 553-562, 2001.

LiMA, S.; LEboUTE, E. M. Resíduo seco da industrialização da uva como alimento para caprinos e ovinos: consumo voluntário e digestibilidade de misturas de resíduo de uva e feno de alfafa. In: REUNIÃO ANUAL DA SOCIEDADE BRASILEIRA DE ZOOTECNIA, 23., 1986, Campo Grande, MS. Anais... Campo Grande: Sociedade Brasileira de Zootecnia, 1986.

Ciênc. agrotec., Lavras, v. 30, n. 4, p. 767-773, jul./ago., 2006 
MERTENS, D. R. Predicting intake and digestibility using mathematical models of ruminal function. Journal Animal Science, Champaign, v. 64, n. 5, p. 1548-1558, 1987.

NATIONAL RESEARCH COUNCIL. Nutrient requirements of sheep. Washington, DC, 1975.

NATIONAL RESEARCH COUNCIL. Nutrient requirements of sheep. Washington, DC, 1985.

NOLLER, C. H.; NASCIMENTO JÚNIOR, D. S. Determinando as exigências nutricionais de animais em pastejo. In: REUNIÃO ANUAL DA SOCIEDADE BRASILEIRA DE ZOOTECNIA, 29., 1982, Piracicaba. Anais... Piracicaba: Sociedade Brasileira de Zootecnia, 1982. p. 412.

OLIVEIRA, W. H.; AROEIRA, L. J. M.; RODRIGUEZ, N. M. Valor nutritivo da cana-de-açúcar adicionada de níveis crescentes de uréia: digestibilidade aparente e partição da digestão. In: REUNIÃO ANUAL DA SOCIEDADE BRASILEIRA DE ZOOTECNIA, 28., 1991, João Pessoa, PB. Anais... João Pessoa: Sociedade Brasileira de Zootecnia, 1991. p. 239.

RAYMOND, W. F. The nutritive value of forage crops. Advances in Agronomy, San Diego, v. 21, p. 1-108, 1969.

SAS INSTITUTE. SAS statistical analysis system: user's guide. Cary, 2004. 846 p.
SILVA, D. J. S.; QUEIROZ, A. C. Análise de alimentos: métodos químicos e biológicos. Viçosa: UFV, 2002. 235 p.

SILVA, J. F. C.; LEÃO, M. I. Fundamentos da nutrição dos ruminantes. Piracicaba: Livroceres, 1979. 380 p.

SNIFFEN, C. J.; O’CONNOR, J. D.; SOEST, P. J. van. A net carboydrate and protein sistem for evaluating cattle diets: II. carboydrate and protein availability. Journal of Animal Science, Champaign, v. 70, p. 3562-3577, 1992.

SOEST, P. J. van. Nutritional ecology of the ruminant. 2. ed. Ithaca: Cornell University, 1994. 476 p.

SOUTO, J. C. R.; ARAÚJO, G. G. L. de; SILVA, D. S. da. Feno de erva-sal (Atriplex nummularia Lindl.) como alternativa para dietas de ovinos no Semi-árido nordestino. 2001. Dissertação (Mestrado em Zootecnia) - Universidade Federal da Paraíba, Areias, 2001.

VERAS, A. S. C.; VALADARES FILHO, S. C.; SILVA, J. F. C. da. Consumo e digestibilidade aparente em bovinos nelores, não castrados alimentados com rações contendo diferentes níveis de concentrado. Revista Brasileira de Zootecnia, Viçosa, v. 1, n. 8, p. 2367-2378, 2000.

VERAS, R. M. L.; FERREIRA, M. A.; CARVALHO, F. F. de. Farelo de palma forrageira (Opuntia ficus-indica Mill) em substituição ao milho. Revista da Sociedade Brasileira de Zootecnia, Viçosa, v. 31, n. 3, p. 1302-1306, 2002. 